\section{A Pd-free High Gold Dental Alloy for Porcelain Bonding}

\author{
JN Wang*, WB Liu \\ School of Materials Science and Engineering, \\ Shanghai Jiao Tong University, \\ Shanghai, 200030, P.R. of China \\ Corresponding author: \\ Tel: +86-21-62932015 \\ Fax: +86-21-62932587 \\ E-mail: jnwang@mail.sjtu.edu.cn
}

\begin{abstract}
Recently, some side effects of Pd, such as allergies, were found, and the risk of using Pd in dental casting alloys was raised. The purpose of the present investigation is to report a Pd-free high gold alloy for porcelain bonding. Emphasis is put on the effect of heat treatment on the mechanical properties of the alloy. The gold alloy was based on the ternary system of $\mathrm{Au}-\mathrm{Pt}-\mathrm{Zn}$ with a nominal composition of $86 \mathrm{Au}-11 \mathrm{Pt}-$ 1.5Zn-0.5In-0.7Rh-0.2Fe-0.1 Ir (wt.\%). Both the hardness and tensile strength of the as-cast alloy can be significantly improved by heat treatment at $980^{\circ} \mathrm{C}$ for 15 min followed by bench cooling, but can't be raised by conventional solution treatment followed by ageing. The strengthening could be attributed to homogenization of microstructure and alloying elements and precipitation of new fine particles. It is suggested that the cast framework of the present new Pd-free alloy could be heat treated before actual firing, and this will improve the processing properties of the alloy during firing.
\end{abstract}

\section{Introduction}

In restorative dentistry, aesthetic care has led to the application of porcelain-fused-to-metal (PFM) techniques. For such application, various types of alloys have been developed. However, noble metal alloys have become the primary selection because a restoration with good aesthetics, good biocompatibility and high toughness can be achieved. Some of these alloys could also be used directly for crowns, fixed partial dentures, and bridges.

Most of the noble metal alloys currently used for the PFM technique are high gold alloys based on the ternary system of Au (80-86\%), Pt (10-15\%) and In (1-2\%) with the addition of Pd (1-2\%) (all compositions in this paper are in weight percentage). Excellent biocompatibility is obtained through the inclusion of high contents of the two noble metal elements, and good hardening is achieved with the addition of In (1). The addition of Pd permits, due to its narrow melting range with $\mathrm{Au}$ and $\mathrm{Pt}$, a sufficient amount of In to be homogeneously dissolved in the alloy. As a result, the mechanical strength of the alloy can be increased to the level for practical utilization (2). But, recently, some side effects of Pd, such as allergies, were found, and the risk of using Pd in dental casting alloys was raised (3). As a matter of fact, such lingering concerns about the biocompatibility of $\mathrm{Pd}$ remain a hindrance for clinical selection of Au-based alloy containing Pd and Pd-based alloy by dental laboratories and practicing dentists. For this reason, Pd-free dental alloys for porcelain bonding are being developed.

It is well known that high-gold PFM alloys often give rise to complaints because of their soft surface, which makes it difficult to trim them after casting. Overlapping on the surface after grinding lead to porosities at the metal-ceramic interface (4). In addition, alloys with a very high gold content have not sufficient creep resistance after casting, and show poor hardness and processing properties. Distortions of the framework due to creep (5-7) lead to an inaccurate fit of the bridge on the master model. Therefore, it is desirable to improve the hardness and strength of the as-cast alloy by heat treatment prior to firing the ceramic on the alloy. It is also important that the alloys have enough hardness and strength to endure the mastication stresses when put into direct use without porcelain veneer. Although effects of heat treatment on mechanical properties of some traditional gold alloys have been investigated, the relevant examinations on Pd-free gold alloys have not been reported.

The aim of the present investigation is to report a Pd-free dental alloy based on the ternary system of Au-Pt-Zn with minor additions of In, Fe, Rh, and Ir. Emphasis is put on the effects of heat treatment on the mechanical properties of the alloy. It is particularly shown that both the roomtemperature hardness and tensile strength of the alloy can't be improved by conventional solid solution treatment followed by ageing, but can be significantly enhanced by a treatment at the temperature usually used for firing followed by a bench cooling process. 


\section{Material and methods}

The alloy used in the present study was a high-gold alloy with a nominal composition of 86Au-11Pt-1.5Zn-0.5In-0.7Rh$0.2 \mathrm{Fe}-0.1 \mathrm{Ir}$. This composition is different from those commercialized ones based on Au-Pt-In-Pd. The additions of $\mathrm{Zn}$ and In are to improve the bonding strength between porcelain and metal and the mechanical properties of the metallic framework. The additions of other elements are primarily for grain refinement and thus improvement of mechanical properties. The alloy was prepared by vacuum arc-melting in argon atmosphere. To minimize compositional segregation and inhomogeneity, the alloy was melted at least three times.

The alloy ingot was cut into small pieces using electrical discharge machining (EDM). They were then remelted and cast by a lost wax casting technique with a universal

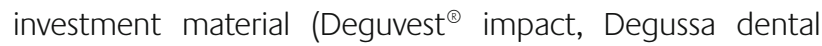
$\mathrm{GmbH} \&$ Co. KG, Germany) and a centrifugal casting machine (Multicast ${ }^{\circledR}$ Compact, Degussa, Germany). The molds were cooled in air before divesting. The obtained specimen was either an alloy cylinder with a diameter of $6 \mathrm{~mm}$ and a length of $40 \mathrm{~mm}$ to be cut into pieces for hardness testing and X-ray diffraction (XRD) or a dog-bone shaped one with a gauge diameter of $3 \mathrm{~mm}$ and a gauge length of $15 \mathrm{~mm}$ for tensile testing in accord with the standard of ISO 9693: 1999(E).

All specimens were divided into three different groups based on the history of heat treatment: (1) specimens that were left in the as-cast state without any further heat treatment (as-cast group); (2) specimens that were heat treated at $980^{\circ} \mathrm{C}$ for 15 min followed by bench cooling in air (the common procedure for porcelain bonding according to the standard of ISO 9693: 1999(E)) (firing-simulated group); (3) specimens that were solution treated at $950^{\circ} \mathrm{C}$ for $30 \mathrm{~min}$ and then quenched into ice water followed by ageing at $450^{\circ} \mathrm{C}$ for up to 10000 min (solution treated and aged

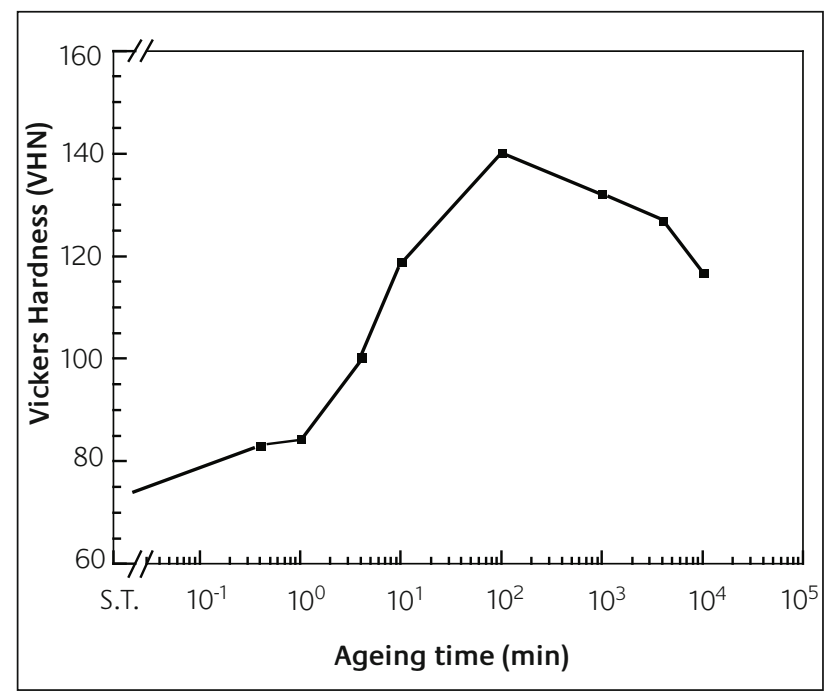

\section{Figure 1}

Age-hardening curve of the present alloy aged at $450^{\circ} \mathrm{C}$ after solution treated at $950^{\circ} \mathrm{C}$ for $30 \mathrm{~min}$. The data for the solution treated (S.T.) state without ageing is included for comparison
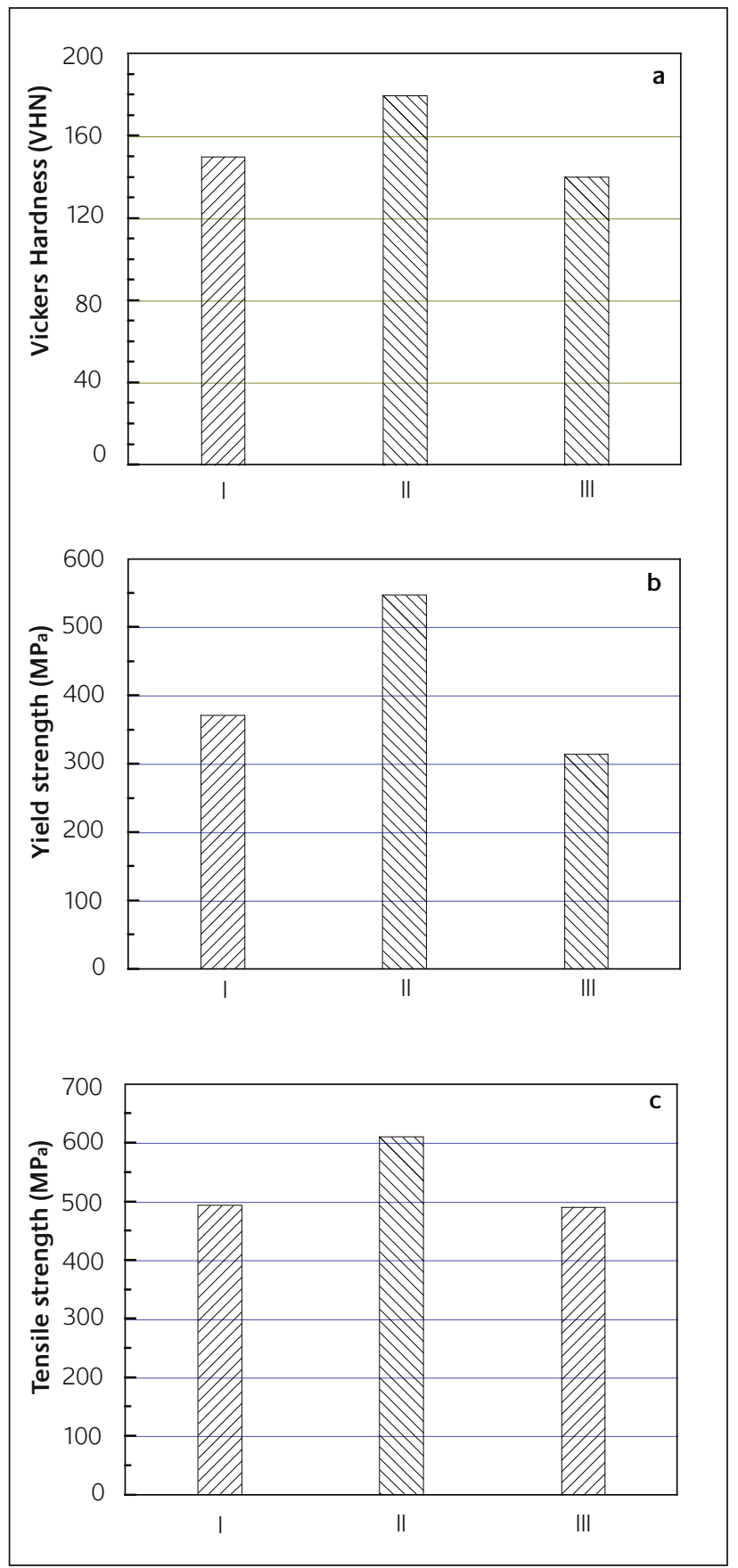

Figure 2

Vickers hardness (a), yield strength (0.2\% strain) (b) and tensile strength (c) of the present alloy in the investigated states: (I) as-cast; (II) firing-simulated $\left(980^{\circ} \mathrm{C}, 15 \mathrm{~min}\right.$, air cooling); (III) peak-aged $\left(450^{\circ} \mathrm{C}, 100 \mathrm{~min}\right)$

group). These treatments were applied both to the plate specimens with a diameter of $6 \mathrm{~mm}$ and a thickness of 1.0 $\mathrm{mm}$ for hardness testing and to the dog-bone shaped specimens for tensile testing.

After the heat treatments, the following tests were conducted. Hardness test was carried out using a Vickers microhardness tester (HX-1000, Shanghai, China) with a load of $300 \mathrm{gf}$ and a dwell time of $45 \mathrm{~s}$. For each alloy state, the mean hardness value was calculated from at least five indentations. The tensile specimens were then precision ground to the end dimensions prescribed by the standard with an accuracy of $\pm 0.01 \mathrm{~mm}$. The tensile test was 
performed with a universal tensile testing machine (Zwick/Roell, Zwick, Germany) at a constant cross-head speed of $1.00 \mathrm{~mm} / \mathrm{min}$ corresponding to a constant strain rate of $1.67 \times 10^{-3} \mathrm{~s}^{-1}$.

Plate specimens of the same size as for the hardness testing were prepared according to the above-described procedure. X-ray diffraction (XRD) experiments were conducted using an X-ray diffractometer (Bruker D8 Advance, Bruker AXS, Germany). The X-ray diffractometer was operated at $40 \mathrm{KV}$ and $40 \mathrm{~mA}$. Nickel-filtered $\mathrm{Cu}$-K $\alpha$ radiation was used in the incident beam. The specimens employed in the hardness testing were also used for metallographic determinations. They were mounted in epoxy-resin. After

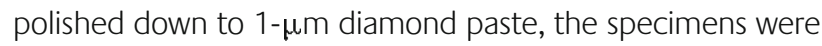
etched with a mixture of $20 \mathrm{ml}$ of $37 \%$ hydrochloric acid and $10 \mathrm{ml}$ of $67 \%$ nitric acid. Microstructure was observed using an optical microscope (Leica MEF4M, Germany). The microstructures and fracture surfaces of the specimens were studied with a field emission scanning electron microscope (FESEM) (Sirion 200, Philips, Holland). Energy dispersive X-ray spectroscopy (EDX) was also used to identify the chemical compositions of the phases in specimens. The approximate spot size of the $X$-ray beam on the specimen surface was about $2 \mu \mathrm{m}$

\section{Results}

\subsection{Mechanical properties}

For the solution treated and aged specimens, the agehardening curve was shown in Fig. 1. Pronounced agehardening occurred at the ageing temperature $450^{\circ}$. It is obvious that the alloy at solution-treated state had a very low hardness. But along with the prolonged isothermal ageing time, the hardness began to increase and reached the maximum value at about 100 min, then decreased gradually with further ageing.

The results of Vickers hardness, yield strength (at $0.2 \%$ strain) and tensile strength are depicted in Fig. 2 for all specimens. Compared to that in the as-cast state, the specimen in the simulated firing state showed higher levels of hardness and strength. For example, the yield strength was increased from $370 \mathrm{MPa}$ to $550 \mathrm{MPa}$. With such an increase, the tensile elongation decreased from $8 \%$ to $6 \%$. This result demonstrates that the alloy was distinctly strengthened with a slight loss of ductility after the simulated firing treatment. But the specimen aged for 100 min (peak ageing) after solution treatment had a slightly lower hardness and tensile strength than the as-cast one. This observation means that the ageing process after solution treatment couldn't raise the hardness and strength of the as-cast alloy.

\subsection{X-ray diffraction}

Figure 3 shows the XRD spectra of the present alloy in the ascast and simulated firing states while Fig. 4 gives those for the specimens after solution heat treatment followed by ageing at $450^{\circ}$ for different periods of time (from 0 to 10000 min). In the as-cast, firing-simulated and solution-treated states, very strong and sharp reflections from a parent $\alpha_{1}$ phase with the face-centered-cubic structure (FCC) were observed. At the same time, $\alpha_{2}$-phase, which also has an FCC structure, was observed in all the investigated states. But its diffraction intensity was very weak. According to the positions of their reflections, the compositions of this alloy and the corresponding ASTM PDF cards (PDF number 040784 for $\alpha_{1}$-phase and PDF number 04-0802 for $\alpha_{2}$-phase), $\alpha_{1}$ and $\alpha_{2}$ phases were identified to be Au-rich and Pt-rich phases, respectively.

Additionally, two extra reflections at $2 \theta$ positions of about $39.2^{\circ}$ and $45.4^{\circ}$ were observed for the as-cast specimen. The corresponding phase of these two reflections was regarded to have an FCC structure, and was termed as $\beta$-phase for the convenience of description. To identify the $\beta$-phase, its lattice constant was estimated to be $a=0.3995 \mathrm{~nm}$ from the X-ray diffraction data (8). This lattice constant is very close to the reported lattice constant of $\mathrm{a}=0.3992 \mathrm{~nm}$ for the binary $\mathrm{Pt}_{3}$ In-phase with a $\mathrm{Cu}_{3} \mathrm{Au}$-type superstructure (9). Thereby the $\beta$-phase is suggested to be $\mathrm{Pt}_{3} \mathrm{In}$, considering the fact that the present alloy contained Pt and In.

Similarly, a new weak reflection appeared at $2 \theta$ position of about $39.2^{\circ}$ for the specimens aged for up to $100 \mathrm{~min}$. The

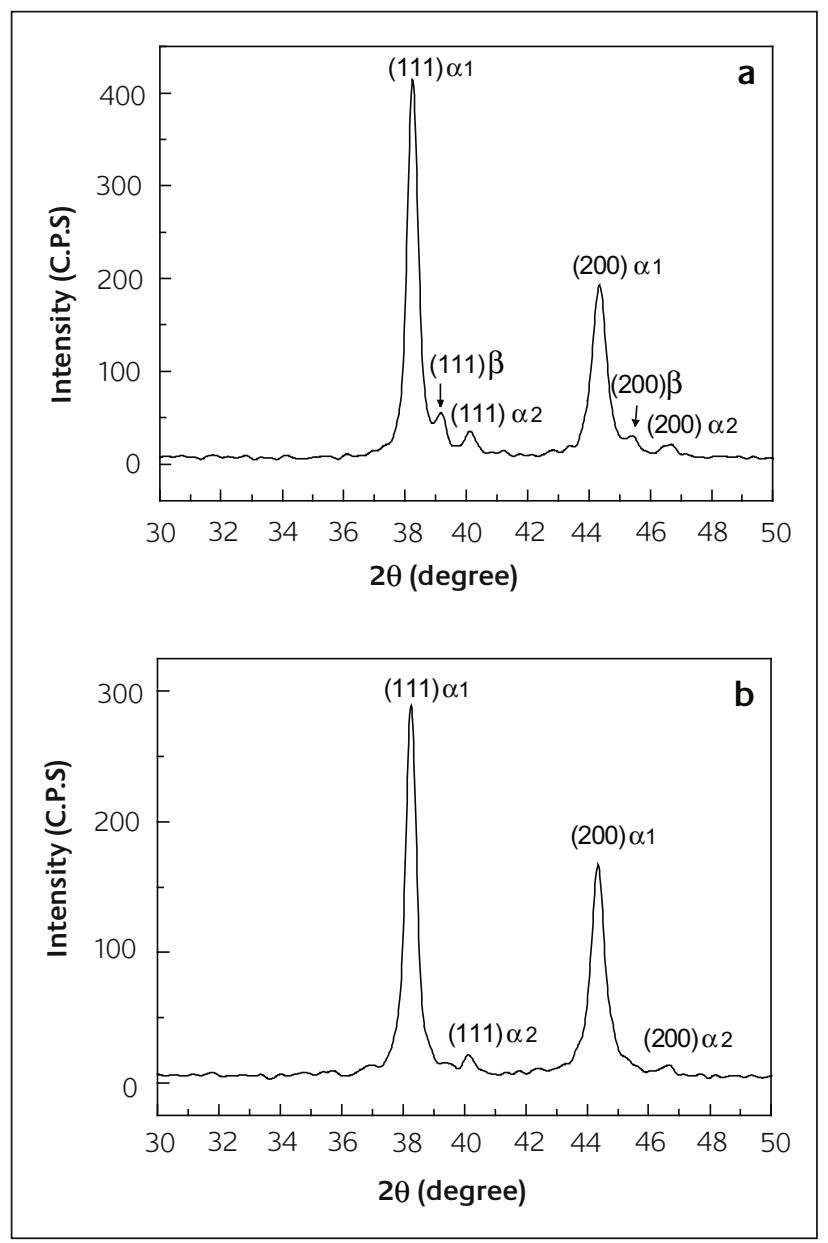

Figure 3

XRD spectra of the present alloy in the as-cast (a) and the firing-simulated (b) states 


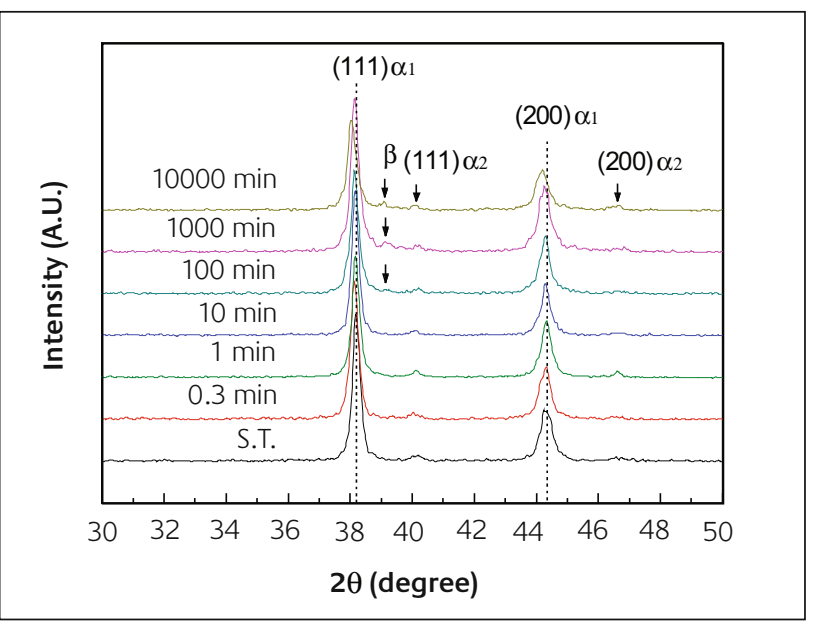

\section{Figure 4}

XRD spectra of the present alloy aged at $450^{\circ}$ for different periods of time

new reflection is believed to result from the above-described $\beta$-phase because its position was just corresponding to that of $\beta$-phase. It should also be noted that the diffraction peaks began to move toward low diffraction angles distinctly after the alloy was aged for more than $100 \mathrm{~min}$.

\subsection{Microstructure}

The metallographic micrographs of the present alloy in its ascast and simulated firing states are given in Figs. 5(a-d). The matrix phase in these two states was identified as an Au-rich $\alpha_{1}$-phase, whereas the other phase, which appeared to be small particles $(\sim 2-10 \mu \mathrm{m})$, was regarded as a Pt-rich $\alpha_{2}$ phase (arrowed in Fig. 5(b,d)). These results were confirmed by EDX analysis. EDX results revealed that the $\alpha_{1}$-phase contained $88-93 \% \mathrm{Au}$, more than 4-7\% Pt and some $\mathrm{Zn}$, while the $\alpha_{2}$-phase contained $55-65 \%$ Pt and $20-30 \%$ Au with some Rh and Fe. Some particles were found to include Pt and In, which may correspond to the $\beta$-phase detected by XRD.

The grain size of the $\alpha_{1}$-phase was approximately identical in both the as-cast and heat treated states ( 30-50 $\mu \mathrm{m})$. Similarly, no distinct difference was found in grain size of the $\alpha_{2}$-phase between the two different states. The as-cast specimen, however, showed an inhomogeneous microstructure within individual $\alpha$ grains. With the imposition of heat treatment, the microstructure became homogeneous, and more $\alpha_{2}$ particles were observed. These fine particles appeared not only within grains but at grain boundaries as well (Fig. 5(d)).

Figures 5(e-g) give the optical microstructures of the alloy in the solution-treated and peak aged states. The solutiontreated microstructure was composed mainly of the parent $\alpha_{1}$-phase and $\alpha_{2}$-phase. While the $\alpha_{1}$-phase existed in the form of equiaxed grains, the $\alpha_{2}$-phase, which still existed after solution treatment followed by ice quenching, appeared in the form of small particles distributing not only at the grain boundaries but within grains as well. It is obvious that the peak aged specimen had a microstructure different from the solution-treated one. Fine precipitates were found within the entire grains of $\alpha_{1}$-phase. This demonstrates that precipitation took place during the isothermal ageing process.

\subsection{Fracture surfaces}

Representative fracture surfaces of the alloy after tensile testing are shown in Fig. 6. The fractographs revealed that specimens in the investigated states fractured with complex mechanisms. Obviously, the fracture surface of the as-cast specimen shows composite characteristics of various sizes of dimples and intergranular fracture. For the specimen after simulated firing treatment, finer uniform dimples were observed. For the peak aged specimen, however, its fracture surface shows less dimples but more intergranular fracturing. Furthermore, fracture also occurred along the phase boundary in the three states and fine heterogeneous particles were observed in grain boundaries.

\section{Discussion}

The present Pd-free dental alloy shows a clear improvement in hardness and tensile strength from the as-cast state to the firing-simulated state (Fig. 2). The results also indicate that the specimen aged for 100 min after solution treatment, which shows the maximum hardness in all the aged specimens (peak ageing), presents a slightly lower hardness and strength than the as-cast one. The reasons for these observations are discussed below.

The immiscibility of Au and Pt in solid state is well known (10). After casting a solid solution nucleates from the melt. During cooling the alloy enters the miscibility gap, separating into an Au-rich and a Pt-rich phase, containing a little of $\beta$-phase detected by XRD. Figs. 5(a-b) and Fig. 6a shows that its microstructure was highly inhomogeneous. With the heat treatment at $980^{\circ} \mathrm{C}$ or $950^{\circ} \mathrm{C}$, the alloy enters the single phase zone between the miscibility gap and the solidus line. At this temperature a solid solution is thermodynamically stable with a random distribution of the atoms in the crystal lattice. The inhomogeneous texture formed after casting therefore is not thermodynamically stable. Owing to the high energy at high temperatures the atoms are able to diffuse in the crystal lattice and forced to distribute randomly on the atomic sites. Subsequently the alloy homogenizes. Then during the cooling process, the homogenized microstructure was mostly maintained (Figs. 5(c-e), Fig. 6b). But a small amount of Pt-rich phase could still precipitate from the solid solution depending on the cooling rate. Thus all the specimens in the present investigation showed a microstructure composed of not only $\alpha_{1}$-phase but some $\alpha_{2}$-phase as well.

After the bench cooling process from $980^{\circ} \mathrm{C}$, the $\beta$-phase disappeared from the XRD spectrum because it had dissolved in the solid solution during the course of high temperature heat treatment. In the ice quenching process, the cooling rate was much faster than that for bench cooling. As a result, 

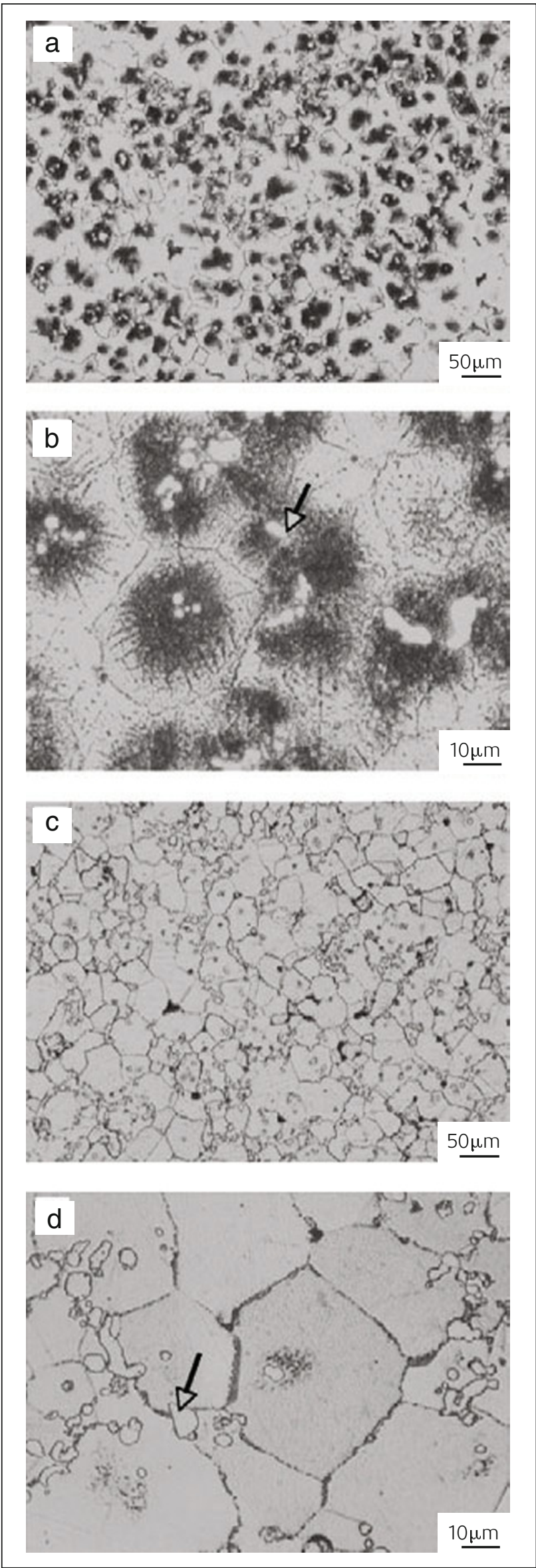

many crystal defects remained and a supersaturated solid solution was achieved. After this treatment, the alloy would be thermodynamically in a metastable state. When the
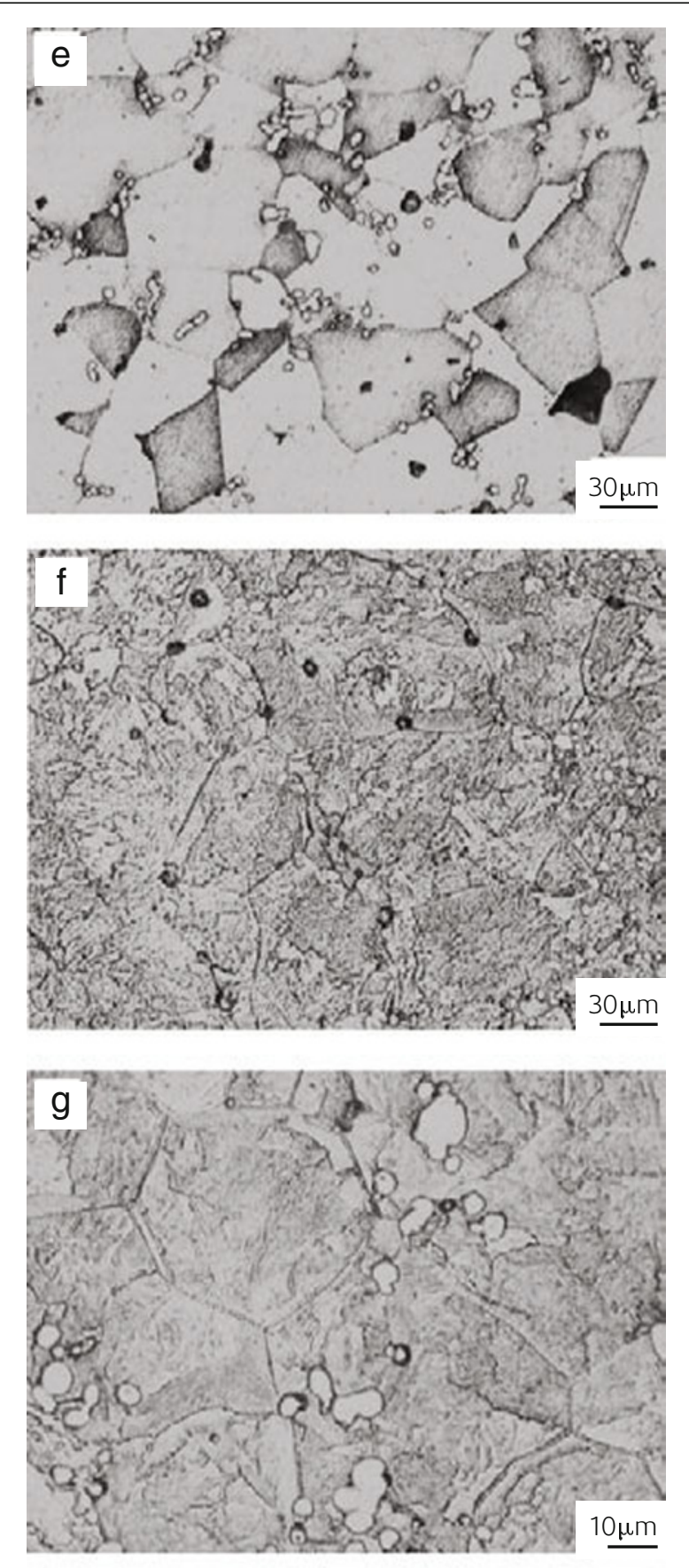

Figure 5

Optical micrographs of the present alloy in the investigated states: as-cast (a, b); firing-simulated $\left(980^{\circ} \mathrm{C}, 15 \mathrm{~min}\right.$, air cooling) (c, d); solution-treated $\left(950^{\circ} \mathrm{C}, 30 \mathrm{~min}\right.$, ice cooling (e); peak-aged $\left(450^{\circ} \mathrm{C}, 100 \mathrm{~min}\right)(f, \mathrm{~g})$

metastable specimens were put under the temperature of $450^{\circ} \mathrm{C}$ to go through the isothermal ageing heat treatment, precipitation reactions occurred driven by diffusion. Many fine precipitates appeared within the grains as shown in Figs. $5(f, g)$, thus led to hardening. However, these precipitates may become the source of intergranular fracturing as indicated by the fracture surface shown in Fig. 6(c).

However, with the ageing time prolonged, the hardness of the present alloy began to decrease gradually. This corresponds to the occurrence of a new phase, namely $\beta$-phase, as detected by XRD (Fig. 4). Compared to the 


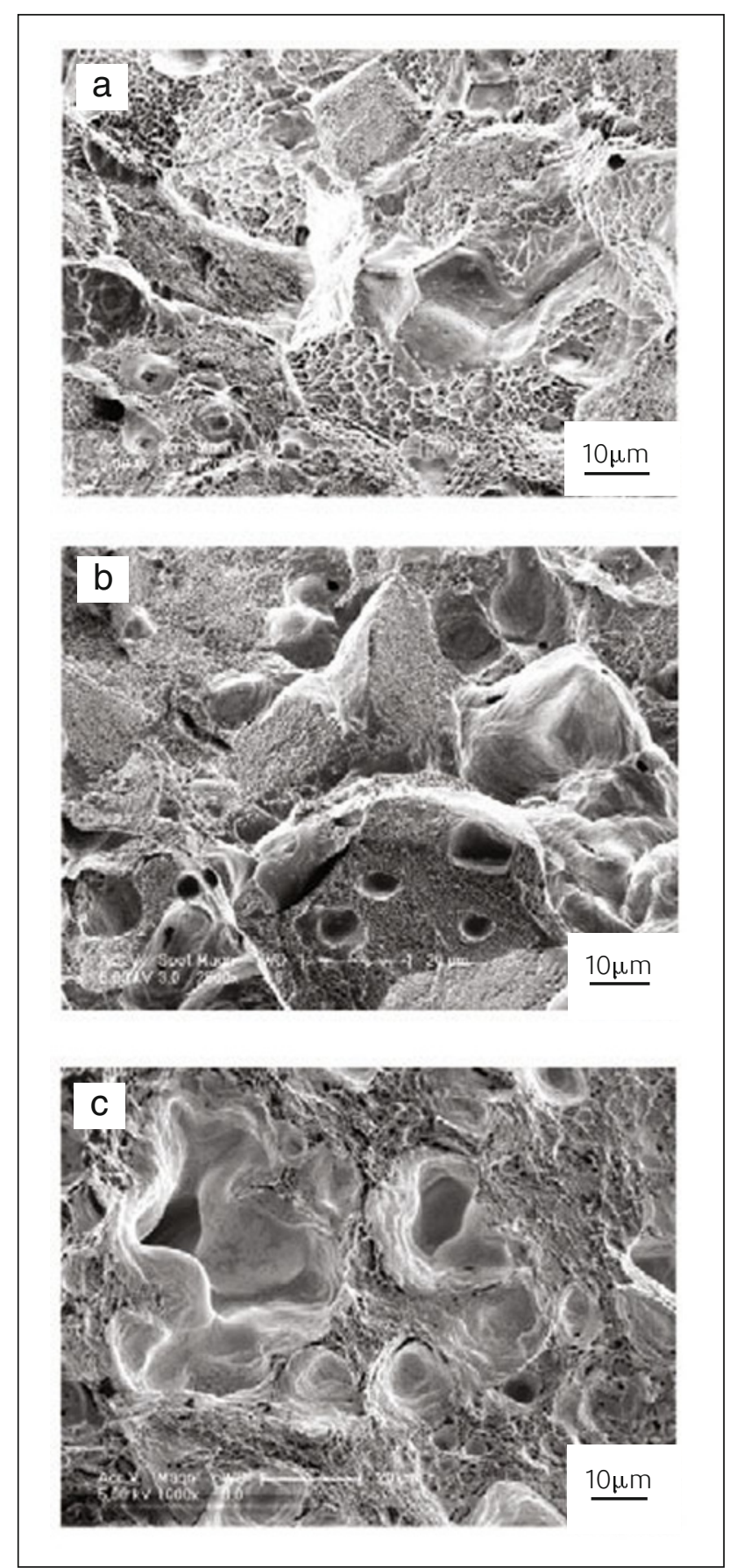

\section{Figure 6}

SEM photographs of fracture surfaces of specimens in different states: as-cast (a), firing-simulated (b); peak-aged (c)

specimens in the as-cast and peak aged states, the specimen in the firing-simulated state, which showed the highest hardness and strength, didn't show the presence of $\beta$-phase (Fig. 3b). Thereby, the improvement of hardness and strength may be related with the elimination of this phase. The reason for this may be that, with the elimination of the $\beta$-phase $\left(\mathrm{Pt}_{3} \mathrm{In}\right)$, more In would be dissolved in the matrix. It is well known that the inclusion of Indium in the ternary system of Au-Pt-In is beneficial to hardening (1). The previous addition of $\mathrm{Pd}$ to this system was actually to increase the solubility of Indium in the alloy matrix (2).

In the ternary alloy of 85.8Au-11Pt-1.7In without Pd (8), the solubility of Indium in the alloy matrix is limited. During ageing at $450^{\circ} \mathrm{C}$ discontinuous precipitation of $\mathrm{Pt}_{3} \mathrm{In}$ took place at grain boundaries, and such precipitation led to a gradual decrease in hardness (8). In order to minimize this detrimental effect of Indium, a much smaller amount of Indium was added (0.5\%) in the present alloy. As shown in this study, such alloying design is beneficial to strengthening.

Based on the results of this study, for the practical application of the present PFM alloy, it is advisable to perform a pre-firing heat treatment. This may be done by annealing the cast framework at $980^{\circ} \mathrm{C}$ for $15 \mathrm{~min}$ immediately after divesting and cleaning the surface, without removing the sprues. By this treatment the alloy will be hardened before being trimmed, thus improving further processing (11). Additionally, casting stresses will be relaxed without deformation of the cast work, thus improving the fit of the reconstruction (12-14).

While firing the ceramic, the alloy is heated for several times to $890-980^{\circ} \mathrm{C}$ and maintained at the temperature for 1-5 min. The present heat treatment could be considered as a firing simulation according to ISO 9693: 1999(E). This is because the heat treatment was conducted at $980^{\circ} \mathrm{C}$, the highest temperature used for firing, for $15 \mathrm{~min}$, the longest time that could possibly be used for firing. In terms of such consideration, it may be deduced that the present alloy would not experience degradation during actual firing.

It is well known that some PFM alloys could also be used directly for crowns and fixed partial dentures. In this case, the alloys usually go through solution treatment and agehardening before being put into practical use. However, the current study indicates that the present alloy couldn't be hardened by conventional ageing. Instead, for the purpose of hardening, the present alloy should be heat treated at high temperature followed by bench-cooling. By this heat treatment, which is simpler than conventional solution treatment and ageing, the mechanical properties of the present alloy can be enhanced to meet the practical requirements in terms of the standard of ISO 1562.

\section{Conclusions}

A Pd-free high gold dental alloy for porcelain bonding is reported. This alloy is based on a ternary system of Au-Pt-Zn with a nominal composition of 86Au-11Pt-1.5Zn-0.5In0.7Rh-0.2Fe-0.1Ir (wt.\%). Both the hardness and tensile strength of the present alloy could be significantly increased by heat treatment at $980^{\circ} \mathrm{C}$ for $15 \mathrm{~min}$ followed by a bench cooling process. The strengthening mechanisms may include homogenization of microstructure and alloying elements and precipitation of new fine particles. Based on these results, it is suggested that the cast framework of such alloy should be heat treated first and the processing properties could then be improved during actual firing. Additionally, when the alloy is used for crowns 
and fixed partial dentures, it should also be heat treated for hardening by the present method rather than the conventional ageing.

\section{Acknowledgements}

This investigation was supported by The Dental Materials Company of Shanghai and The National Natural Science Foundation of China.

\section{About the authors}

JN Wang: Group leader, professor of Materials Science. B.Sc. in 1984, and Ph.D. in 1991. Currently working on development of new metallic materials (including gold alloys). Having authored or co-authored more than 100 technical papers published in international journals.

WB Liu: M.Sc. in 2006. Presently working in a company located at Shanghai.

\section{References}

1 K.F. Leinfelder, W.J. O’Brien, G. Ryge, C.W. Fairhurst, J. Dent. Res. 1966, 45, 292

2 J. Fischer, H.K. Guo, M. Salk, Dtsch. Zahnärztl. Z. 1994, 49, 636

3 J.C. Wataha, C.T. Hanks, J. Oral Rehab. 1996, 23, 309

4 M. Yamamoto, The metal ceramics. 1982, Tokyo: Quintessence.

5 J.J. Tuccillo, J.P. Nielsen, J. Dent. Res. 1967, 46, 579

6 R.A. Bryant, J.I. Nicholls, J. Prosthet. Dent. 1979, 42, 515

$7 \quad$ R.L. Bertolotti, In: W.J. O'Brien (ed.), Dental materials: properties and selection 323, 1989, p. 240. Chicago: Quintessence

8 T. Shiraishi, M. Ohta, J. Mater. Sci.: Mater. Med. 2002, 13, 979

9 I.R. Harris, M. Norman, A.W. Bryant, J. Less-Comm. Met. 1968, 16, 427

10 T.B. Massalski (ed.), Binary alloy phase diagrams American Society for Metals, 2nd edition, 1990, Metals Park, OH: American Society for Metals

11 J. Fischer, P.W. Fleetwood, Dent. Mater. 2000, 16, 109

12 S.D. Campbell, L.B. Pelletier, J. Prosthet. Dent. 1992, 68, 284

13 S.D. Campbell, A. Sirakian, L.B. Pelletier, R.A. Giordano, J. Prosthet. Dent. 1995, 74, 476

14 K.J. Anusavice, C. Shen, D. Hashinger, S.W. Twiggs, J. Dent. Res. 1985, 64, 1094 